\title{
Main Stages of Evolution from Mechanical Automatic Systems to Humanoid Robot
}

\author{
Ionel Staretu \\ Product Design, Mechatronics and Environment Department, Product Design and Environment Faculty, Transylvania University of \\ Brasov, Brasov 500036, Romania
}

Received: June 09, 2015 / Accepted: July 08, 2015 / Published: May 25, 2015.

\begin{abstract}
Since ancient times, man has been concerned to create an artificial structure similar to itself. This concern has remained constant attention and creative thinkers most profound since antiquity until today, it is of greatest interest. This article aims to highlight the most significant moments of the evolution from mechanical creatures mythical or real, from antiquity to the present humanoid robots. There are thus shown the most significant variants humanoid imagined or realized since Talos, described in Greek mythology, continuing with mechanical machines during late Roman Empire, the Byzantine Empire and then the Renaissance of the post-renaissance, then they are shown the main achievements of the industrialization period from the nineteenth to the early part of the twentieth century, then to the most important made in the last decades of the twentieth century and early twenty-first century. The work is important to stimulate concerns academic theorists and practice but also in the industrial practice specializing in robotics and more generally in mechatronics. It also opens the prospect of defining the concept of an artificial humanoid useful both for human prosthesis with certain disabilities, and a humanoid robot performance.
\end{abstract}

Key words: Mechanical automate, humanoid robot, service robot, medical robot, robotics market.

\section{Introduction}

Creating artificial structures similar to the man himself was constant attention to the most profound and creative scholars throughout history and today through a period of maximum interest.

Historically, the first automatic (the term coming from the Greek word automatos-moving on its own) mechanical humanoid system can be considered the legendary Talos (Fig. 1). This one, described in several texts from antiquity, had a human-like mechanical structure and it was driven by a special liquid. According to some texts, Talos was probably forged of bronze, by Hephaestus and the Cyclopes and given to King Minos of Crete as a gift. Talos was intended to defend Crete from potential invaders but also to stop the locals to leave the island without the

Corresponding author: Ionel Staretu, Ph.D., professor, research fields: robotics, gripping systems, biomechanisms, mechanisms, virtual reality applied in robotics, medical robotics, virtual engineering. E-mail: staretu@unitbv.ro. will of the king and to make sure that the king's laws are observed. On this purpose, he used to patrol up and down the island, going around Crete three times a day, which means a speed of $350 \mathrm{~km}$ per hour, something still impossible even today. In order to work, Talos was based on a single red vein, most likely a network of veins, located under artificial skin, rather a breastplate, from the neck to the heel, being closed by a bronze nail.

The nail was sealed in the divine ichor (a kind of blood of the gods), and the liquid in the vein allowed the metal limbs to move. The heel was the only weak point of his body. Talos lost functionality when Medea gave him a drink, which made him fall asleep, and she removed the bronze nail so that the liquid in the vein has leaked out. Even though Talos probably never existed physically, he has always been a starting point for making real versions of him.

Actually, Greeks were always concerned to achieve the most complex automatic mechanical systems. 


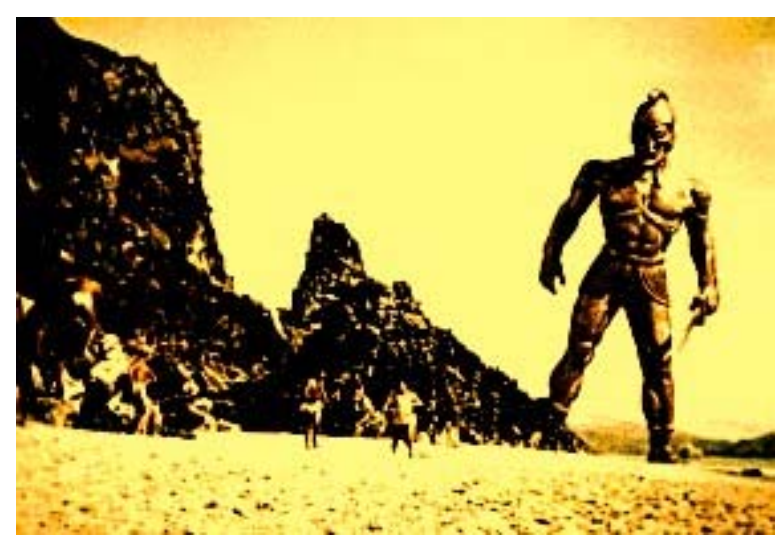

Fig. 1 Talos in an artistic representation [1].

Thus, it may be mentioned that in the year $350 \mathrm{BC}$ (before Christ), the mathematician Arhitas built a mechanical bird, named the Dove, actuated by steam. Then it is further recorded that in $322 \mathrm{BC}$, Aristotle wrote, foreshadowing the development of mechanical automation, in the current perspective of robotics: "If every tool could perform, controlled or on its own initiative, the activity that it can do at maximum efficiency ... then there would be no need for apprentices for the master's workers or for slave to serve masters". At the same time, Ctesibios of Alexandria and Philon of Byzantium described more human-like and animal-like automatic systems. In addition, Hero of Alexandria described as well a group of puppets that were used in miniature theatrical shows, operated by a complex system of counterweights, and mechanical parts such as levers and even gears.

\section{Mechanical Automata of the Renaissance}

Until the Renaissance around the 1500s, we no longer knew data about other versions of automatic humanoid systems, but progress in this regard was continuous. To show that the interest in creating the artificial man remained constant since ancient times, including to the first part of the Middle Ages, we remind the golem achievement. It was an artificial being made by Rabbi Judah Loew ben Bezalel, who lived in Prague in the sixteenth century. It is supposed to have been created using occult powers, which he was said to be endowed with.

It should also be mentioned the complex mechanical machines that were made including in the Roman Empire, called quite recently the Byzantine Empire, functional around 900, described by Liutprando da Cremona, diplomat at the court of Emperor Constantine VII, where he gets in 949. He describes a room called Magnaura (translated the big Zephyr) where he saw two mechanical lions active from the kinematic point of view, at the scale 1:1, which flanked the throne of the emperor of Constantinople, throne that could be raised and lowered, and mechanical birds chirping.

Obviously, these achievements must be made in conjunction with the University of Constantinople, which was at that time a large-scale scientific institution until the conquest of Constantinople in 1453.

It is worth highlighting as well the fact that a part of this description was taken and presented under the title The Byzantine robot by the well-known writer Umberto Eco in the book entitled The Book of Legendary Lands, published in 2013. Certainly, many of the achievements of the University of Constantinople were transferred to Western Europe, especially in the current Italy. It may be mentioned that the university was founded by the Emperor of Constantinople Theodosius II, in the year 425. Initially, 31 departments had focused on theoretical science but also applied as: medicine, geometry , astronomy and later polytechnic, including, applied mechanics (Fig. 2). Chronologically, it should be recognized as the first European university, compared to one in Bologna, usually considered today as the oldest, which was founded only in 1118.

In this context, it is easier to explain the quite successful attempt by Leonardo da Vinci to create a mechanical lion and a medieval knight in mechanic armor. The robot was a warrior dressed in armor, and was able to make more gestures: place, moving arms, neck movement, raising his helmet visor. The robot was driven by a series of pulleys and cables (Fig. 3). 


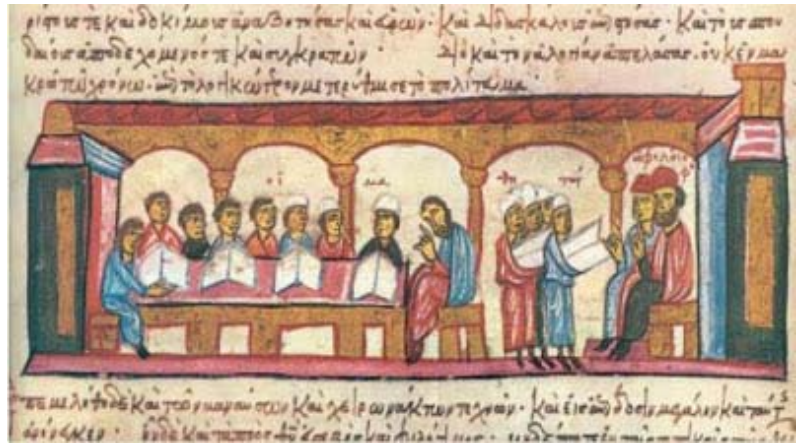

Fig. 2 University of Constantinople [2].

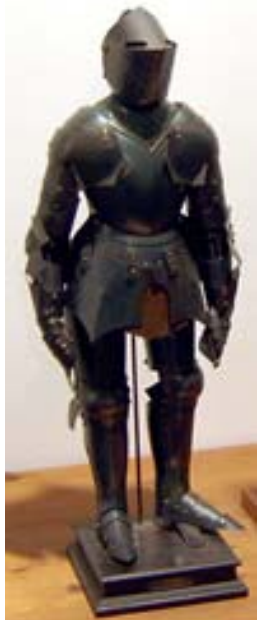

(a)

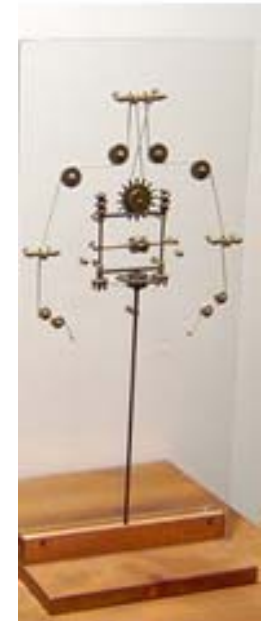

(b)
Fig. 3 Knight's robot Leonardo da Vinci: (a) moving outer armor, inside (b) the system drive [3].

This last achievement can be considered the forerunner of today's humanoid robot. In the following period, after 1500, there have been multiple attempts to achieve various automatic systems to imitate human activities, especially artistic ones, of remarkable complexity and functionality. Thus, it is highlighted the Flute Player of Vaucanson (made and exhibited at the Louvre in 1738) and the Tambourine Player, in the same year (Fig. 4). The Flute Player is distinguished by extremely complex building which was based on a one meter long cylinder with a diameter of $1.56 \mathrm{~m}$, which contained, in relief, in the form of cams, controls required for operation in the required sequence, which is further transmitted by mechanisms. There were 15 levers eight of which served to change blowing air (air pressure control three, one for the movement of the tongue, lips and

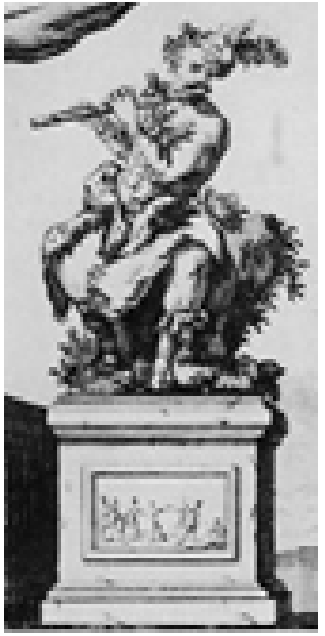

(a)

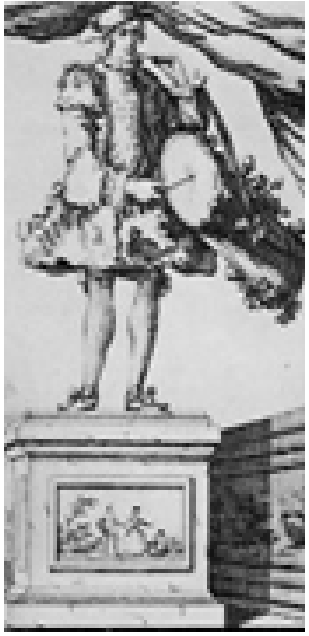

(b)
Fig. 4 (a) Flute player and (b) tamburine player by Vaucanson [4].

four for movement), and seven serving to order the fingers (three for left hand and the right hand four). The machine was powered by an engine based energy storage shuttle. Cleverly, it was due to the fact that three tanks placed inside the chest could get three intensities of airflow. The fingers were glued portions of real leather. Flutists interpret 12 songs that lasted a quarter of an hour. Vaucanson had been concerned about artificial human achievement to end of life. Thus pursuing an artificial circulatory system, tried possibility of artificial speech (by achieving jaws, lips and an artificial language), reaching the idea of a machine able to articulate vowels. All this is very interesting given the current concerns in these directions.

Not much later was conducted the humanoid automaton able to write a text - the writer belonging to Pierre Jacquet Droz (1768); the harpsichord performer of the same master (Fig. 5); the eardrum performer Kintzing (1774), etc.

The automatic systems of this period are characterized by the finesse of the details, the accuracy of their practical realization and high functionality, even if limited in time. Many of the solutions used were developed based on mechanical watches systems, which at this time reached very high levels of complexity, and on other devices such as navigation 


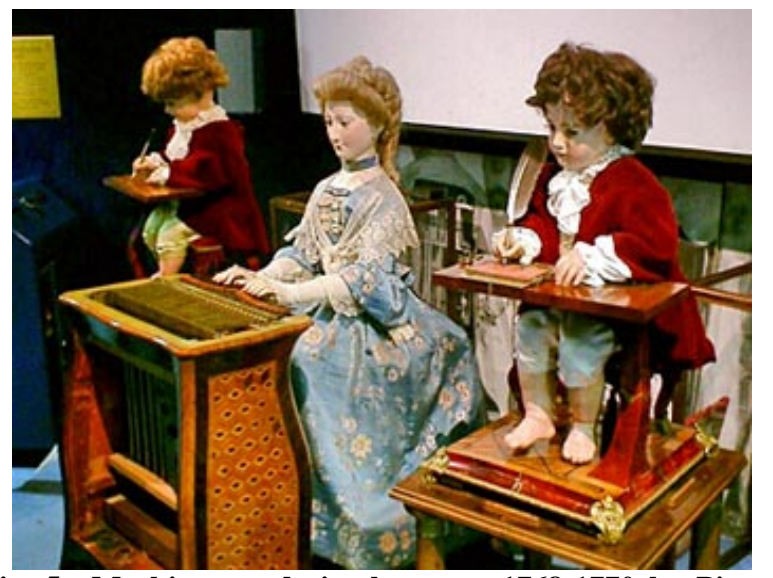

Fig. 5 Machines made in the years 1768-1770 by Pierre Jaquet Droz: the scribe (in two versions) and the harpsichord performer [5].

systems. An important part of the solutions used in these machines was then successfully applied in the industrial revolution of the 19th century.

\section{Automatic Systems Post-renaissance until} the Early 20th Century Improved Acquisition

In the next period, it can be mentioned even some mechanical orchestras, the first is attributed to Maelzel, for which Beethoven himself wrote the first part of the composition Opus 91, Wellington's victory. These orchestras included flutes, clarinets, trumpets, triangles and strings, which were driven by air pipes and little hammers. A mechanical violinist, probably inspired by Maelzel's machines was presented in 1838 at the Conservatoire in Paris, and was considered a success.

Another desire expressed in the period of medieval automatic systems was making a machine able to play chess, which resulted in a sophisticated enough form, at the beginning of the twentieth century, by Leonardo Torres y Quevedo, Spanish engineer and mathematician.

\section{From Mechanical Automata to Current Humanoid Robots}

After a calm period in this direction, interest will be reiterated relatively intensely in the mid twentieth century, after launching the concept of robot by Karel Capek in the play R.U.R., in 1920, by making several humanoid mechanical automatic systems, though rather rudimentary. The true start of making, this time, humanoid robots, activities which continue today too, with great prospects even in the near future, was given in the 70s in Japan, which culminated with the famous robot ASIMO achievement (Fig. 6), in continuous improvement today.

\subsection{Modularization of Humanoid Robots}

In this context, it can be mentioned that the humanoid robot can be approached from the modular perspective too, consisting of: head module, body module, arms module, and locomotion module (legs, if bipedal robots) [7]. Each module can be developed relatively independently provided to finally obtain a unitary assembly and at the same time really functional.

Regarding the implications of modularization can mention the two concepts under which you can interpret human body. The first concept is the traditional one, according to which the human body is a complex system which in turn consists of several subsystems: subsystem circulatory, respiratory

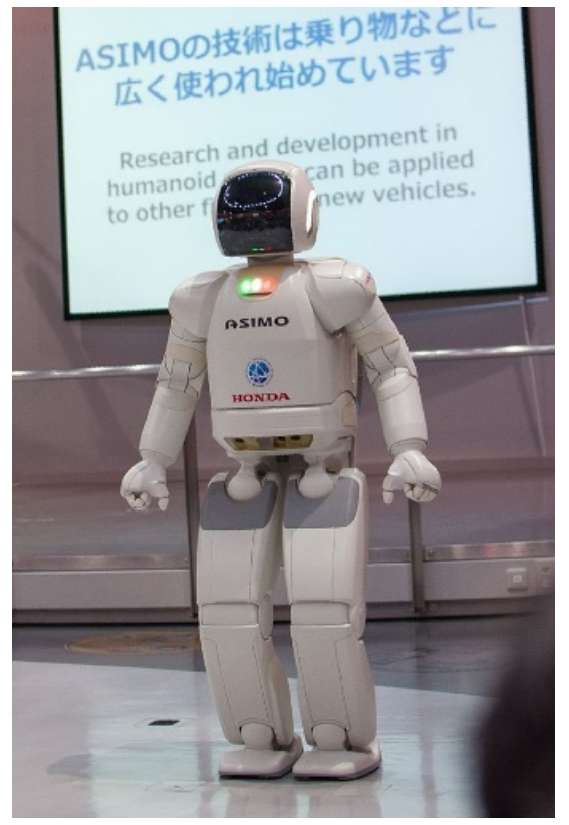

Fig. 6 The robot ASIMO 2014 [6]. 
subsystem, subsystem nervous, digestive subsystem, etc. These subsystems are more or less interconnected, but can be addressed relatively separate, regarding implementation of artificial component such as bionic eye or artificial heart, or from the perspective of applying therapies or treatments that are somewhat geared specifically to one of these component subsystems or some of them, such as heart surgery or treatment given. The second concept we introduced in 2005 in Ref. [7] believes that there is a superior material organized, cerebral matter, as the human brain, which is served by several structures and subsystems, for interaction with the environment: the senses for receiving external stimuli, limbs moving and handling; chemicals needed to process life: various internal organs (liver, pancreas, kidney, etc.) or even subsystems as: subsystems circulatory, respiratory subsystem, etc. From this perspective, the brain is the coordinating center for the entire body thus maintaining optimum operating condition and returning it in case of occurrence of malfunctions. In Fig. 8 is shown a simplified diagram of this approach. Considering brain structures and subsystems serving as structural-functional modules, it is acceptable that any can be replaced with an artificial proper version. This opens the prospect of bionic man, the brain naturally be served by more or fewer subsystems artificial prosthesis man more or less, and perspective humanoid robot with human brain. In this regard, current experiments on transplanting head [8] must be properly considered that transplanted body, the brain is essential to ensure the control and operation of the new body under the orders generated by it.

Opening brightest prospects robots with brain is already done by many experiments underway, as described in Ref. [9], which refer to the realization of a mobile robot controlled by a guinea pig brain. Currently there are more achievements in humanoid robots. These robots although it differs substantially from the human body, as the reference model, have some features that approaching it. Thus ASIMO, the

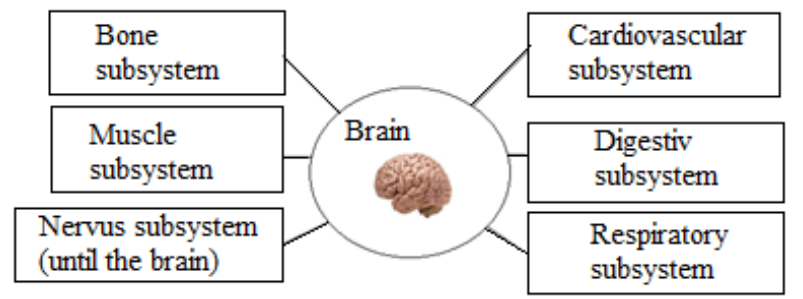

Fig. 8 The brain is serviced by several specialized subsystems (there are shown six examples only).

2014 version is a humanoid robot but more like a cosmonaut, with 57 degrees of mobility, $1.30 \mathrm{~m}$ tall, weighing about $55 \mathrm{~kg}$ with a speed of $9 \mathrm{~km} / \mathrm{h}$ (it can go up and down the stairs and slopes and it can even dance), which understands and speaks Japanese and English, it can make a presentation, it can react to human gestures, it can manipulate various objects and it can shake hands.

\subsection{Significant Versions of Humanoid Robots}

Below we present several significant aspects to create a suggestive image of humanoid robotics today. First, we signal the intention, already partially materialized, of a company in Japan to hire 1,000 robots (Fig. 9) as sellers in its stores to sell coffee makers. This robot named Pepper, is 120 centimeters tall, it moves on rollers, it has a tablet-console on the chest for interaction, it understands $70-80 \%$ of spontaneous conversations, and will be sold at a price of about \$2,000 each, from the first part of 2015.

Robots of this kind work already in over 70 mobile phone stores owned by SoftBank in Japan, now their job is being to greet customers.

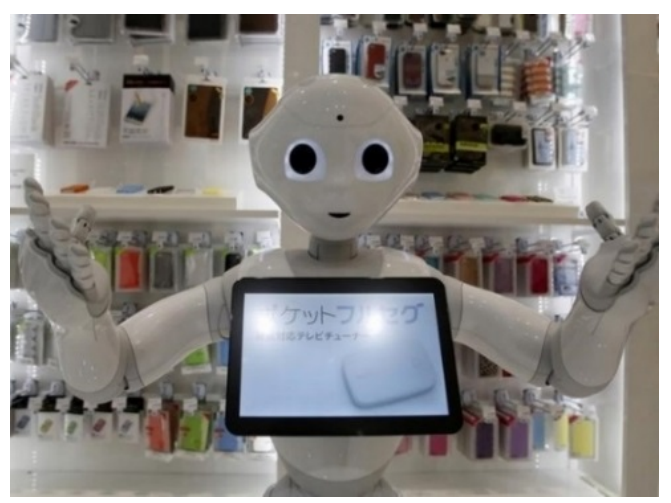

Fig. 9 Pepper robot [10]. 
Another robot is Robroy, considered one of the most advanced humanoid robots, developed at the University of Zurich. This is a robot modeled after the human structure, having for actuation, tendons similar to human ones. It is a robot designed to execute independently services for people, sharing workspace with them. It has artificial skin, which ensures it a better integration in the environment where it will work, alongside human operators. Bipedal humanoid or partially humanoid robots, on rollers, generally are expected to be used as nannies, nurses, emergency medical personnel, waiters, drivers, medical assistants, accountants, salespersons in shops, hotel staff, marketing staff, etc.

In this context, the well-known Bill Gates's statement is suggestive, claiming that: Substitution by software programs, whether it is drivers, waiters or nurses ... it happens at this time. Technology, in time, will decrease the demand for jobs, especially for people who are not highly trained. In 20 years from now, labor demand for a lot of jobs will be substantially reduced. The author do not think people understand that. Also, the futurologist Ray Kurzweil, who wrote several books about the technological singularity (when artificial intelligence will dethrone the human mind), estimates that the machines will be smarter than humans by 2029 and in 2045 they will be billions of times more powerful compared to human intelligence.

The same author anticipates the transformation of Homo sapiens, in a not too distant future, in Cyber sapiens hybrid creatures partly biological, partly digital.

These issues lead us to scenarios in which the labor market will be completely transformed by software and robots, even if people exceed their physical limits with the aid of particularly advanced mechatronic devices such as exoskeletons, but also of sensory and intellectual ones, by systems that increase visual and auditory capabilities, and even increase cognitive capacities. In these circumstances, it can be mentioned that more and more people take advantage of the latest technological breakthroughs to improve their body and senses with various gadgets-devices, parts and mechatronics mechanisms and we can say that we are witnesses of the foundations of a truly new species: Homo Roboticus.

In this context the humanoid robot will become a regular companion of man, becoming customary in his close proximity both in the domestic environment (Fig. 10), as a companion and support robot, and in the work-job environment, as a partner in solving tasks specific to activities of most companies that we know today.

So already, now, utilitarian robots are used for a wide range of services including supervision and cleaning both in households and in hospitals and hospices. Besides, given that the world's population ages, this kind of robots will also help to ensure the autonomy of the elderly. Other areas of real interest for the humanoid robots are those of entertainment and sports. Several types of robots that can perform various artistic activities, such as robots that can play various instruments: flute, trumpet, violin, etc.-modern versions of medieval machines, are being made, or they are already manufactured. In addition, the robots intended to practice various sports, especially football are of certain actuality, already being organized soccer championships for teams of robots; moreover, robots are expected to have their own Olympic Games, China wanting to organize the first edition in the city of Harbin.

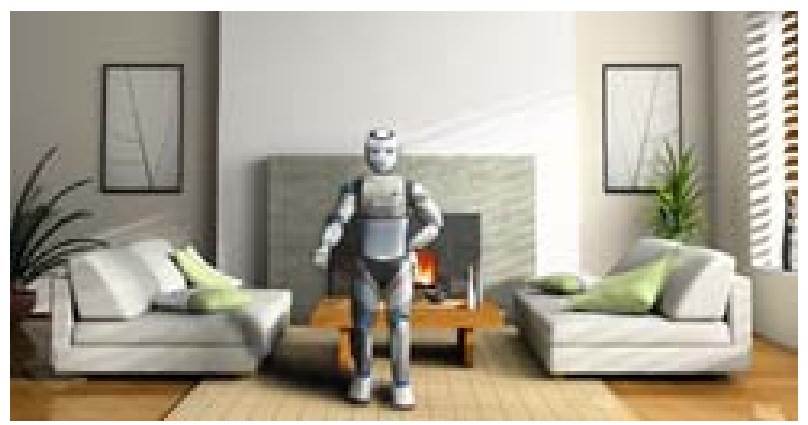

Fig. 10 An humanoid robot in the domestic environment [11]. 


\subsection{Humanoid Robots Market}

To achieve in practice what we have shown, considerable funds are necessary, but also great demand for robots, which seems feasible according to the manager of the company InnoRobo, Brunn Bonnell, who said some time ago that for 2010-2013 was estimated the sale of 6.7 million units. As far as the robotics market is concerned (Fig. 11) it has doubled since 2005, reaching $\$ 24.9$ billion in 2008, and it is estimated its tripling by 2025, when it hits about 75 billion dollars.

Moreover, humanoid robots for company are expected to be the next major step in consumer appliances. In the category of humanoid robots we can mention as well the robots: Poppy, BioRob 2008, NAO, Icub, PETMAN, Aiko, Kobian, Albert Hubo, Roboray, Romeo, etc., each with different features and functional and constructive particularities that tend to relate them as much as possible to the human model (Fig. 12).

A particularly challenging area is related to obtaining humanoid robots that are very difficult to distinguish from people. This is an area as challenging as it is real, and of great perspective that will
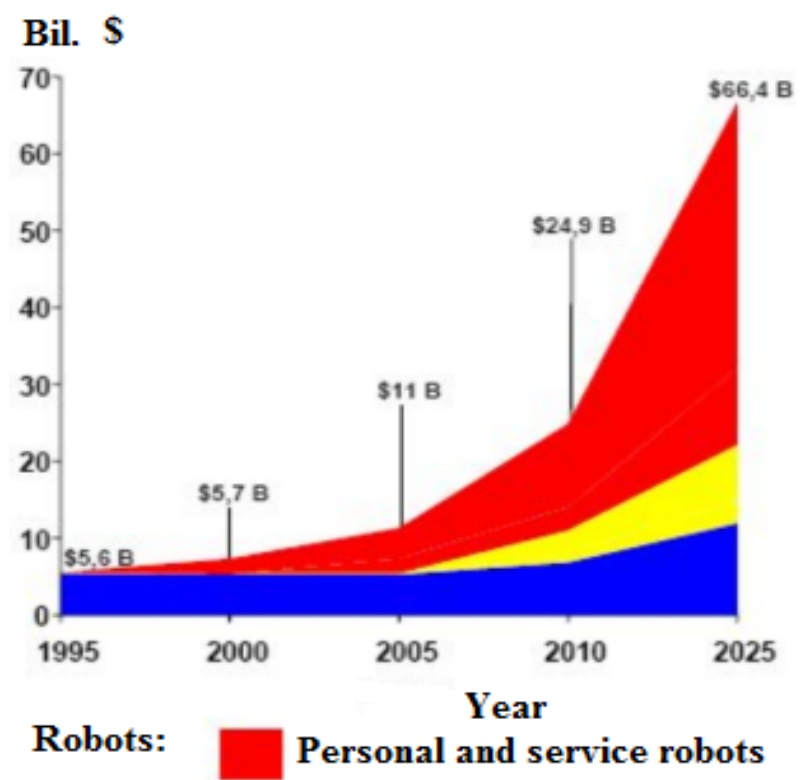

Medical robots $\square$ Industrial robots

Fig. 11 Robotics market evolution by 2025 [12].

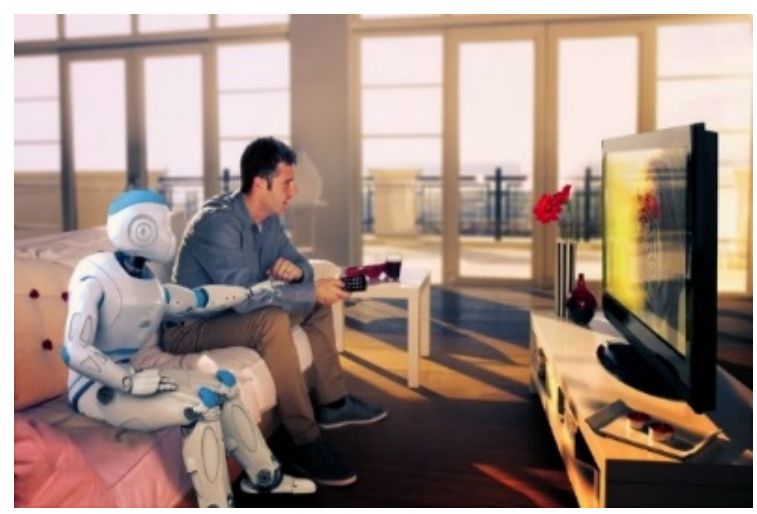

Fig. 12 Humanoid robot as man's partner [13].

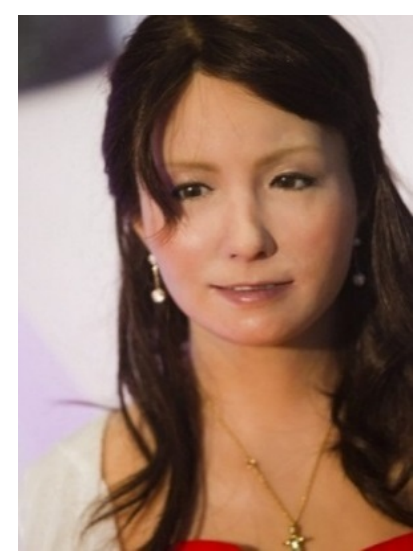

Fig. 13 Geminoid F robot [14].

fundamentally change human society as we know it today. As an example, here is the latest achievement of the Japanese teacher Hiroshi Ishiguro from Osaka University namely the robot called Geminoid F (Fig. 13).

It can smile, it can move the mouth while speaking and singing and it can simulate 65 facial expressions, such as expressions of amusement and enigmatic moods, it may raise eyebrows with a total of 12 motor structures under the plastic artificial “skin”. The price of this robot, currently exhibited in a shopping center in Hong Kong, is \$110,000, still very high, but it certainly will drop sharply in the coming years. Obviously, such a robot can be an actor too, profession that can be added to those already mentioned that could be performed by robots.

At the end of this study it should be noted that concerns for making humanoid robots existed in our country too, which unfortunately remained at the level of intent. In this context, we mention the monographic 
book Elements of Medical Robotics and Prosthetics [8], which the author published in 2005, which has a chapter entitled: Humanoid robot-robot sapiens, which provides an overview of the level of this area at the time, with intention to generate concerns and concrete achievements including using some of the solutions presented personally. The author also mention the proposal that the author made at the Summer School: ISRIS (International School on Robotics and Intelligent Systems), Iasi, 2009, namely to start a comprehensive integrated project to achieve bionic man following two concrete directions: prostheses for almost any body part and making an advanced humanoid robot, which is still topical, under the title: Total Prosthesis Application in the Human Body - an Innovative Concept for Rehabilitation and Humanoid Robots. Anatomic and Physiological Bases and Technical Solutions.

Obviously, in the next period such concerns can be brought to the attention of researchers, engineers, robotics and mechatronics experts, in both academic environment and in manufacturing of potential mechatronic, the market for such products, as can be deduced from the existing data, having very encouraging potential in the near future.

\section{Conclusions}

The following conclusions can be drawn from those presented in this paper:

- robotics of services, which include humanoid robots has an upward dynamics that is obvious now and will be kept in the future too;

- humanized robots tend to be very similar to humans, with advanced functionality and aesthetics;

- already several models of humanoid robots are commercially available and they will become a regular companion of man before long;

- concerns for the development of humanized robot models are of interest in Romania too, which can have important results.

\section{References}

[1] Talos Mechanical Automatic Systems. Accessed 2015. http://www.thescifishow..../talos-in-jason-and-the-argona uts/.

[2] http//www.johnsanidopoulos.com201105university-of-co nstantinople-founded-in.html. Accessed 2015.

[3] http://en.wikipedia.org/wiki/Leonardo\%27s_robot. Accessed 2015.

[4] http://en.wikipedia.org/wiki/Jacques_de_Vaucanson. Accessed 2015.

[5] Droz, J. P. The Scribe (in Two Versions) and the Harpsichord Performer. http://www.snipview.com/q/ Jaquet-Droz...automata.

[6] ASIMO Robot. 2014. Accessed 2015. http://en. wikipedia. org/wiki /..... ASIMO_2014.jpg.

[7] Staretu, I. 2005. Elemente de Robotică Medicală și Protezare/Elements of Medical Robotics and Prosthetics. Brasov: Lux Libris Publisher. (in Romanian)

[8] http://en.wikipedia.org/wiki/Head_transplant. Accessed 2015.

[9] http://www.sciencegadget.com/will-selfconscious-robot-b e-the-next-naturalevolution/. Accessed 2015.

[10] Pepper Robot. http://www.hngn.com/....-2015.html.

[11] Humanoid Robot. Accessed 2015. http:// www.nspyre.ro /news /3649 /.

[12] Robot Market. Accessed 2015. http:// www. nspyre .ro /news/3649/.

[13] Humanoid Robot. http://www.activistpost. com/2013/07/...robot.html.

[14] Geminoid F Robot. Accessed 2015. http://www.google. ro/search?q=\%5B14\%5D\%09Geminoid+F+robot\&biw. 